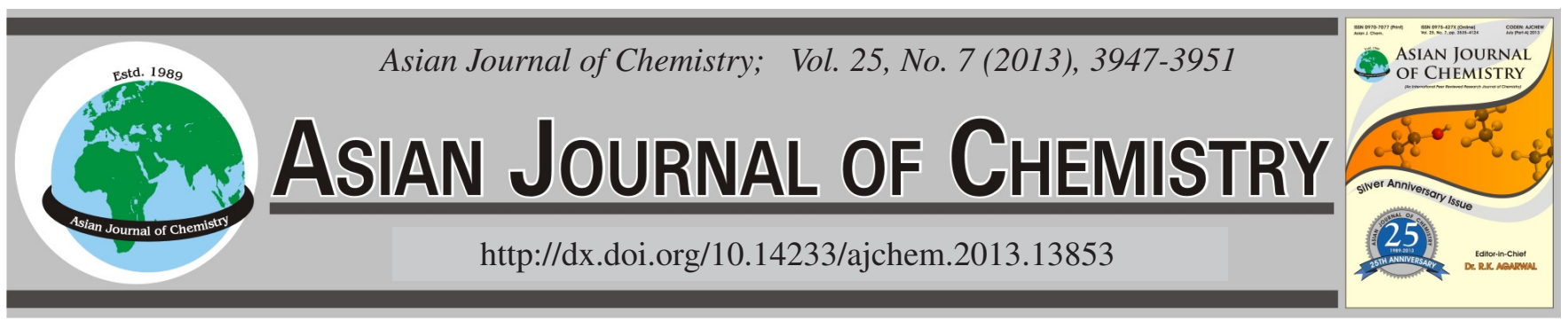

\title{
Adsorption and Persistence of Ziram Fungicide in Allahabad Region Soils Influence by Organic Matter
}

\author{
Ritesh Kumar Srivastava ${ }^{1}$, BriJesh K. Singh ${ }^{2}$ and Dinesh Mani, ${ }^{1, *}$
}

${ }^{1}$ Department of Chemistry, Sheila Dhar Institute of Soil Science, University of Allahabad, Allahabad-211 002, India

${ }^{2}$ Department of Chemistry, Moti Lal Nehru National Institute of Technology, Allahabad-211 004, India

*Corresponding author: E-mail: dr.dinesh.au@gmail.com

(Received: 5 April 2012;

Accepted: 18 January 2013)

AJC-12729

\begin{abstract}
The adsorption isotherms of Ziram obey the Freundlich equation $\left(r^{2}>0.99\right)$ very well. Adsorption of Ziram increases in following order, black > sandy loam $>$ alluvial soil in untreated and farm yard manure treated soils. Adsorption isotherm was non linear with $1 / \mathrm{n}_{\text {ads }}$ values $<1$. The product of the Freundlich adsorption constants $\left(\mathrm{K}_{\mathrm{f}}\right)$ showed good correlation with the soil organic matter content which suggests that soil organic matter is the main controlling factor for Ziram adsorption. Cation exchange capacity, clay and $\mathrm{pH}$ content of the soil also affect the adsorption constants. The negative magnitude of Gibbs free energy $(\Delta \mathrm{G})$ indicates that the adsorption was exothermic and spontaneous process. The persistence of Ziram indicates a close correspondence to the $\left(\mathrm{r}^{2}>0.97\right)$ first order exponential degradation kinetics and it is mainly influenced by soil organic matter. The half-life $\left(T_{1 / 2}\right)$ value of Ziram was observed to be highest for alluvial soil followed by sandy loam and black soils.
\end{abstract}

Key Words: Adsorption, Persistence, Ziram, Fungicide, Half-life, Farm yard manure, Organic matter.

\section{INTRODUCTION}

Ziram $\{$ zinc-bis(dimethyldithiocarbamate) $\}$ is an agricultural dithiocarbamate fungicide used on a wide variety of plants. It is applied to the foliage of plants, used as seed dressing, soil treatment and as foliar treatment in different crops $^{1}$. Ziram is used primarily on almonds and stone fruits. It is also used as an accelerator in rubber manufacturing, packaging materials, adhesives and textiles. It is also used as bird and rodent repellent ${ }^{2}$. In Ziram, presence of zinc in combination with the dithiocarbamate made it more effective against Taphirna, Coryneum, scab, rusts, phytophtora and Septoria ${ }^{3}$. Progressive production and application of chemicals in agriculture as well as in plant protection and animal health has converted the problem of environmental pollution into international issues. Adsorption of pesticides by soil is one of the most important factors affecting their bioavailability, degradation, volatilization and transportation to aquatic environments ${ }^{4}$. Adsorption also determines availability of pesticide in the soil solution that governs the amount of pesticide that is available for uptake by plants. Adsorption of pesticide is an important process which controls all other processes such as their movement, persistence, degradation and determines the fate of pesticide in soil system $^{5}$. The extent of adsorption is generally determined by various soil properties including organic matter content, content of clay, $\mathrm{pH}$ and cation exchange capacity (CEC). Out of these parameters, organic matter and cation exchange capacity of soil plays a predominant role in adsorption ${ }^{6}$.

Few research papers are published concerning the environmental fate of Ziram and its metabolites. Degradation of Ziram for 30-50 days in field experiments indicates a low to moderate persistence $^{7,8}$. The degradation of Ziram depends upon many factors like soil $\mathrm{pH}$, salinity, organic matter, moisture, temperature, type and pesticide concentration ${ }^{4}$. The present study was designed to evaluate the adsorptive characteristics of Ziram in soils of Allahabad region that are significantly different in organic matter and other physical and chemical properties. The sorption behavior of Ziram was correlated with selected soil properties in an attempt to better understand the factors that influences adsorption. The degradation of Ziram in soils was also measured to determine the degradation kinetics.

\section{EXPERIMENTAL}

Sample collection and standardization: Three types of soils viz. alluvial, sandy loam and black were collected from different places of Allahabad district having different physicochemical properties. All the samples were air dried and grinded to pass through $2 \mathrm{~mm}$ sieve. These soils were kept in desiccators to avoid contact with moisture. Physiochemical properties (Table-1) like cation exchange capacity (CEC) were determined by neutral $1 \mathrm{~N}$ ammonium acetate solution, organic 
TABLE- 1

PHYSIOCHEMICAL PROPERTIES OF SAMPLE SOILS BEFORE AND AFTER FARM YARD MANURE TREATMENT

\begin{tabular}{|c|c|c|c|c|c|c|c|c|c|}
\hline \multirow[b]{2}{*}{ Soils (texture) } & \multicolumn{3}{|c|}{ Mechanical composition } & \multicolumn{2}{|c|}{$\mathrm{pH}$} & \multicolumn{2}{|c|}{ Organic carbon $(\%)$} & \multicolumn{2}{|c|}{$\mathrm{CEC}\left[\mathrm{C}\left(\mathrm{P}^{+}\right) \mathrm{mol} \mathrm{kg}^{-1}\right]$} \\
\hline & Sand $(\%)$ & Silt (\%) & Clay $(\%)$ & $\mathrm{A}$ & B & A & B & A & $\mathrm{B}$ \\
\hline Alluvial & 57.2 & 23.8 & 19.0 & 6.2 & 6.8 & 0.23 & 0.41 & 19 & 30 \\
\hline Sandy loam & 64.5 & 17.3 & 18.2 & 7.8 & 8.2 & 0.47 & 0.57 & 25 & 62 \\
\hline Black & 51.4 & 24.2 & 24.4 & 7.2 & 7.3 & 0.57 & 0.65 & 28 & 74 \\
\hline
\end{tabular}

carbon (OC) by chromic acid digestion method and $\mathrm{pH}$ by using digital $\mathrm{pH}$ meter in soil water (1: 2.5) suspension. Silt and clay were separated by the pipette method and fine sand was separated out by decantation'. Farm yard manure was used as a source of organic matter at the rate of $25 \mathrm{tha}^{-1}$. The physiochemical properties of these soils before and after farm yard manure treatment is given in Table-1.

Technical grade Ziram fungicide was obtained from India pesticide limited Lucknow, India and used as such as received without further any purification. The chemical formula, structure and physical properties of Ziram fungicide are given in Fig. 1 [m.f.: $\mathrm{C}_{6} \mathrm{H}_{12} \mathrm{~N}_{2} \mathrm{~S}_{4} \mathrm{Zn}$, m.w.: 305.8, appearance: off white powder, m.p.: $240-244^{\circ} \mathrm{C}$, solubility in water: $\left.65 \mathrm{mg} / \mathrm{L}\left(25^{\circ} \mathrm{C}\right)\right]$.

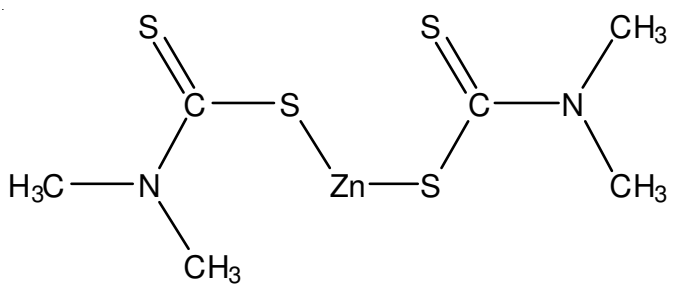

Fig. 1. Chemical structure of Ziram

Sample preparation: For adsorption study, stock solution of Ziram fungicide was prepared in $0.5 \mathrm{~N}$ sodium hydroxide. Concentration of the working solution used for adsorption studies were 25, 50, 75 and $100 \mu \mathrm{g} / \mathrm{mL}$. One gram air-dried soil was taken in four of the five test tubes. $10 \mathrm{~mL}$ of the working solution (Ziram) was added in all the tubes. The fifth tube, which did not contain soil, was used as a reference. The tubes were shaken for different time intervals $(0.50,0.75,1,1.5,2$, $2.5,3,5$ and $8 \mathrm{~h}$ ). The equilibrium time was found to $2 \mathrm{~h}$ and was used in the adsorption studies. Thereafter tubes were taken out and centrifuged for $20 \mathrm{~min}$ at $1000 \mathrm{rpm} .5 \mathrm{~mL}$ of aliquot from each tube was taken out and filtered. For every soil, experiments comprised of one duplicate and one reference was performed for one concentration of Ziram. Similar experiments were conducted with other natural (untreated) soils and soils with farm yard manure (FYM) contents at four concentrations. The supernatants were collected for adsorption studies and analyzed by colorimetric method at $380 \mathrm{~nm}$ using cuprous chloride reagent ${ }^{10}$.

For persistence studies, $100 \mathrm{~g}$ of well sieved soils were taken in petridishes and $20 \mathrm{~mL}$ of standard solution $(100 \mu \mathrm{g} / \mathrm{mL})$ of Ziram was applied to the soils under laboratory conditions. Every experiment was performed in duplicate. In another set of treatment, farm yard manure was used as a source of organic matter. The analysis of Ziram remaining in untreated and treated (farm yard manure) soils was carried out of $0,3,6$ and 9 days.
Experimental procedure: In our present study, two methods were used to analyse Ziram fungicide. A titrimetric method, commonly known as "carbon disulfide evolution method" was performed to estimate a higher amount of Ziram. The second method i.e., colorimetry, was used for the estimation of comparatively lower doses of Ziram by using a cuprous chloride reagent ${ }^{10}$. To perform this experiment, $30 \mathrm{~mL}$ of lead acetate solution was added to the first absorption tube attached with distillation apparatus and $25 \mathrm{~mL}$ of methanolic potassium hydroxide in the second absorber and $5 \mathrm{~mL}$ of methanolic potassium hydroxide in each of the bubblers. Water was allowed to flow through the condenser. The sample was put into the digestion flask. Dropping funnel and air bleed was assembled to add $20 \mathrm{~mL}$ tetra sodium EDTA through funnel. Absorption train was connected to a controlled vacuum supply so that approximately three bubbles of air per second or $50 \mathrm{~mL} / \mathrm{min}$ could pass through the system. Sample was well dispersed by swirling the flask gently for $c a .1 \mathrm{~min}$ and then $50 \mathrm{~mL}$ boiling $\mathrm{H}_{2} \mathrm{SO}_{4}$ (4 $\mathrm{N}$ aqueous) was quickly added through dropping funnel and flask was immediately heated with a naked flame. Brisk rate of reflux was maintained until the sample was fully decomposed ( $c a$. 25-30 min) and then cooling condenser was stopped for 2-3 min. During this period the condenser and the first absorber were flushed with steam to remove any entrapped carbon disulfide $\left(\mathrm{CS}_{2}\right)$. The burner was removed and the absorption chain was disconnected. The contents of the methanolic potassium hydroxide absorber and bubblers were washed. Two drops of phenolphthalein indicator were added and neutralized with acetic acid and continuous stirring by glass rod. The solution was titrated with iodine using starch indicator.

Method of calculation: The amount of the Ziram fungicide was calculated by following formula

$$
\left[\operatorname{Ziram}(\%)=15.29 \times \mathrm{t} \times \frac{\mathrm{n}}{\mathrm{w}}\right]
$$

$1 \mathrm{~mL}$ of $0.1(\mathrm{~N})$ iodine $=0.01529 \mathrm{~g}$ of Ziram $), \mathrm{t}=$ titration reading, $\mathrm{n}=$ exact normality of iodine solution and $\mathrm{w}=$ weight of sample.

The adsorption isotherm was analyzed by Freundlich equation $\log \left(\mathrm{C}_{\mathrm{s}}\right)=\log \left(\mathrm{K}_{\mathrm{f}}\right)+1 / \mathrm{n}_{\text {ads }} \log \left(\mathrm{C}_{\mathrm{e}}\right)$ where $\mathrm{C}_{\mathrm{s}}\left(\mu \mathrm{g} \mathrm{g}^{-1}\right)$ is the amount of fungicide adsorbed by soil, $\mathrm{C}_{\mathrm{e}}\left(\mu \mathrm{g} \mathrm{mL^{-1 }}\right)$ is the equilibrium concentration in solution and $\log \mathrm{K}_{\mathrm{f}}$ and $1 / \mathrm{n}_{\mathrm{ads}}$ are empirical coefficients representing the intercept and slope isotherm, respectively ${ }^{11}$.

The $K_{f}$ values were normalized to the organic matter (OM) content of soil and calculated using the following equation $^{11}$

$$
\mathrm{K}_{\mathrm{om}}=\frac{\mathrm{K}_{\mathrm{f}}}{\mathrm{OM}} \times 100
$$


The distribution coefficient $\left(\mathrm{K}_{\mathrm{d}}\right)$ for each soil was calculated using the following equation ${ }^{12}$

$$
\mathrm{K}_{\mathrm{d}}=\frac{\Sigma\left(\mathrm{C}_{\mathrm{s}} \cdot \mathrm{C}_{\mathrm{e}}\right)}{\Sigma\left(\mathrm{C}_{\mathrm{e}}\right)^{2}}
$$

where, $\Sigma$ indicates the summation of the values.

The change in the Gibb's free energy for adsorption was calculated using the following equation ${ }^{11}$

$$
\Delta \mathrm{G}^{\mathrm{o}}=-\mathrm{RT} \ln \left(\mathrm{K}_{\mathrm{f}}\right)
$$

where $\Delta \mathrm{G}^{\mathrm{o}}$ is Gibb's free energy change $\left(\mathrm{KJ} \mathrm{mol}^{-1}\right), \mathrm{R}$ is gas constant $\left(8.314 \mathrm{~J} \mathrm{~mol}^{-1} \mathrm{~K}^{-1}\right)$ and $\mathrm{T}$ is absolute temperature (Kelvin).

In the persistence studies, the amount of pesticide residues that remained at different intervals were fitted to first order exponential decay equation is $\mathrm{C}_{\mathrm{t}}=\mathrm{C}_{\mathrm{o}} \mathrm{e}^{-\mathrm{K}}{ }_{\mathrm{deg}}^{\mathrm{T}}$, where $\mathrm{C}_{\mathrm{t}}$ is the concentration after time, $\mathrm{T}$ (days), $\mathrm{C}_{\mathrm{o}}$ is initial concentration and $\mathrm{K}_{\mathrm{deg}}$ is rate constant $\left(\right.$ day $\left.^{-1}\right)$. The half life was computed using following equation ${ }^{11}$

$$
\mathrm{T}_{1 / 2}=\left[\frac{0.639}{\mathrm{~K}_{\mathrm{deg}}}\right]
$$

\section{RESULTS AND DISCUSSION}

The adsorption of Ziram by three soils is represented by isotherms (Fig. 2). The adsorption of Ziram increased with increasing initial concentration but the per cent adsorption decreases with increasing concentration. The adsorption isotherms were concentration dependent. The adsorption isotherms of Ziram in soil classified as L type of the Giles classification $^{13}$. The $\mathrm{L}$ shaped isotherm signifies that there is relatively high affinity between Ziram and soil particles and there is not much competition from water molecules. The isotherms indicate that greater amount of Ziram was adsorbed in the order of black soil $>$ sandy loam soil $>$ alluvial soil. The higher adsorption on black soil was observed due to relatively more organic matter content and neutral soil $\mathrm{pH}$ as compared to other soils. Sharma et al. and Kumar et al. established the role of organic matter in adsorption of organic molecules in soils $^{14,15}$.

All sorption isotherms satisfactorily described by the Freundlich equation with correlation coefficients $\left(R^{2}>0.99\right)$ which is shown in Table-2. For adsorption, Ziram isotherm marked curvature with slopes $\left(1 / \mathrm{n}_{\mathrm{ads}}\right)$ significantly less than

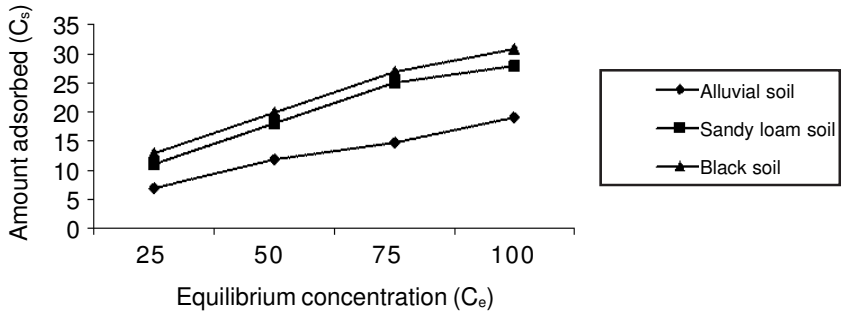

Fig. 2. Adsorption isotherm of Ziram on untreated (natural) soils

unity (0.512-0.650). this is due to fact that only a small portion of theoretically available soil surface is available for sorption. That the Ziram sorption was dependent on the range of concentration used and $1 / \mathrm{n}_{\mathrm{ads}}$ values calculated at lower concentration range was significantly higher than those at the higher range ${ }^{16}$.

The magnitude of $\mathrm{K}_{\mathrm{f}}$ values for all three soils ranges from 1.080-3.585 depending on individual soils. The $\mathrm{K}_{\mathrm{f}}$ values indicate strong sorption of Ziram in soils. In general, $\mathrm{K}_{\mathrm{f}}$ values are in accordance with the organic matter content of the soils. The highest $\mathrm{K}_{\mathrm{f}}$ value was recorded for the black soil which has the highest organic matter content. The $\mathrm{K}_{\mathrm{f}}$ value decreases in the same order as organic matter content i.e., black soil > sandy loam soil > alluvial soil.

The correlation between sorption and soil properties can be used not only to predict the sorption of pesticide on different soil but also to elucidate the factors of soil that dominate in the sorption process. Linear regression analysis between sorption coefficient $\left(\mathrm{K}_{\mathrm{f}}\right)$ and soil properties were also performed and the results are shown in Table-3. The highest correlation was obtained when organic matter was used as soil property $(\mathrm{P}=0.1418)$. The correlation coefficient between $\mathrm{K}_{\mathrm{f}}$ and $\mathrm{pH}$, cation exchange capacity and clay were also significant and there was no significant correlation between $\mathrm{k}$ and other soil properties. The correlation between $\mathrm{K}_{\mathrm{f}}$ and soil properties was positive which indicates that the extent of adsorption increases as the organic carbon, organic matter clay or cation exchange capacity increases ${ }^{17}$.

The Ziram adsorption in farm yard manure treated soils are given in Fig. 3. The isotherms were non linear. Addition of organic matter by farm yard manure did not change the pattern of adsorption but the quantity adsorbed at each concentration increases as compared to untreated soil (Fig. 3). This increase could be related to the sorption of organic matter to the soil by increasing the sorption sites available for adsorption.

\begin{tabular}{|c|c|c|c|c|c|c|c|c|c|c|c|c|}
\hline \multirow{2}{*}{ Soils } & \multicolumn{6}{|c|}{ Untreated (natural) soil } & \multicolumn{6}{|c|}{ Treated (soil containing FYM) } \\
\hline & $\mathrm{K}_{\mathrm{f}}$ & $1 / \mathrm{n}_{\mathrm{ads}}$ & $\mathrm{r}^{2}$ & $\mathrm{~K}_{\mathrm{om}}$ & $\mathrm{K}_{\mathrm{d}}$ & $\Delta \mathrm{G}$ & $\mathrm{K}_{\mathrm{f}}$ & $1 / \mathrm{n}_{\mathrm{ads}}$ & $\mathrm{r}^{2}$ & $\mathrm{~K}_{\mathrm{om}}$ & $\mathrm{K}_{\mathrm{d}}$ & $\Delta \mathrm{G}$ \\
\hline Alluvial & 1.080 & 0.650 & 0.99 & 272.37 & 0.27 & -13.89 & 3.098 & 0.534 & 0.99 & 438.24 & 0.53 & -15.07 \\
\hline Sandy loam & 2.358 & 0.588 & 0.99 & 290.93 & 0.49 & -14.06 & 4.480 & 0.469 & 0.99 & 455.90 & 0.62 & -15.17 \\
\hline Black & 3.585 & 0.512 & 0.99 & 364.81 & 0.57 & -14.62 & 9.332 & 0.324 & 0.99 & 832.74 & 0.81 & -16.66 \\
\hline
\end{tabular}

TABLE- 2

ADSORPTION KINETICS OF ZIRAM IN SOILS

TABLE- 3

LINEAR REGRESSION ANALYSIS FOR FREUNDLICH ADSORPTION CONSTANT $\left(\mathrm{K}_{\mathrm{f}}\right)$ AND SELECTED PROPERTIES OF SOILS

\begin{tabular}{lccccccc}
\hline \multicolumn{1}{c}{ Linear regression parameter } & $\mathrm{pH}$ & O.C. $(\%)$ & O.M. $(\%)$ & Clay $(\%)$ & Sand $(\%)$ & Silt $(\%)$ & CEC \\
\hline Slope & 0.9729 & -0.6194 & 4.0972 & 0.2947 & -0.0823 & 0.0113 & 0.2690 \\
Intercept & -4.5339 & 6.9930 & -0.6499 & -3.7106 & 7.0887 & 2.0600 & -4.1150 \\
Significant level $(\mathrm{P})$ & 0.5679 & 0.1411 & 0.1418 & 0.4165 & 0.7162 & 0.9746 & 0.1136 \\
Correlation Coefficient $\left(\mathrm{r}^{2}\right)$ & 0.6279 & 0.9755 & 0.9753 & 0.7935 & 0.4312 & 0.0399 & 0.7841 \\
\hline
\end{tabular}




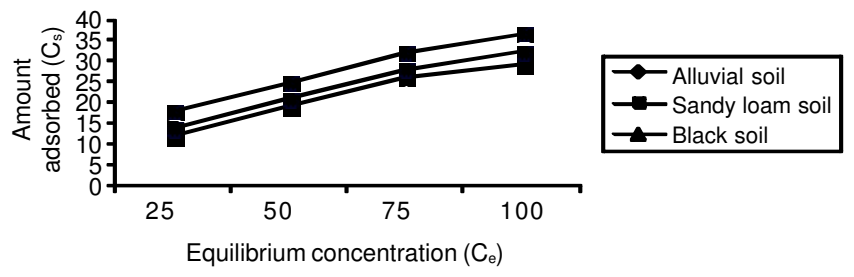

Fig. 3 Adsorption isotherms of Ziram on treated (farm yard manure) soils

The interaction between pesticide and organic matter occur via multiple bonding mechanisms which includes ionic bonding between negative charged organic matter and positively charged pesticide and hydrogen bonding in between pesticide and organic matter ${ }^{18}$.In treated soil, maximum adsorption occurs in black soil followed by sandy loam and alluvial soil. This suggests that the organic matter and clay content plays important role in adsorption of Ziram which is further controlled by soil $\mathrm{pH}$ and type of clay. Though, in farm yard manure treated soils there was marked difference in the magnitude of adsorption but the shape of adsorption isotherms remained same. The Freundlich constant $\left(\mathrm{K}_{\mathrm{f}}\right)$ values for Ziram in farm yard manure treated soil were greater than those in corresponding untreated soils which indicate that organic matter is most important factor in adsorption ${ }^{19}$.

Distribution coefficients $\left(\mathrm{K}_{\mathrm{d}}\right)$ is a measure of the soil adsorption capacity because it represents the relationship between the concentration of Ziram in the solid (soils) and in the liquid (soil solution) for a given equilibrium concentration. The higher $\mathrm{K}_{\mathrm{d}}$ values of black soil followed by sandy loam and alluvial soil again confirm the above order of adsorption ${ }^{20}$. The values of $\left(\mathrm{K}_{\mathrm{d}}\right)$ increases with the addition of farm yard manure (Table-2). The value was found minimum in alluvial soil and maximum in farm yard manure treated black soil. These results confirm the role of organic matter as primary absorbing component for the Ziram fungicide. Similar trend has been observed by Mandal and Adhikari ${ }^{12}$.

The free energy $(\Delta \mathrm{G})$ value of $40 \mathrm{KJ} \mathrm{mol}^{-1}$ was considered as a threshold for identifying the physical and chemical mechanism of adsorption and physical adsorption mainly was involved below the threshold ${ }^{21}$. The free energy $(\Delta \mathrm{G})$ of Ziram have negative values (Table-2) which shows that the sorption is spontaneous and exothermic process ${ }^{11}$. Further low value of $\Delta \mathrm{G}$ revealed more or less physical nature of sorption on the soil organic matter surface. The heat of Ziram sorption released range at $25^{\circ} \mathrm{C}$ between -12.21 to $-13.99 \mathrm{KJ} \mathrm{mol}^{-1}$ for untreated soil and for treated soil -12.21 to $-13.99 \mathrm{KJ} \mathrm{mol}^{-1}$ (Table-2). The $\Delta \mathrm{G}$ of Ziram in three soil less than $40 \mathrm{KJ} \mathrm{mol}^{-1}$, indicating that the adsorption of Ziram by three soils was mainly a physical process. The adsorption of Ziram by soils also was a spontaneous process for the negative value of $\Delta \mathrm{G}$. The Ziram sorption is temperature dependent and is exothermic in nature in different soil ${ }^{20}$.

Persistence is mostly affected by photo-degradation, chemical and microbial degradation. All these processes may participate in the breakdown of a single pesticide ${ }^{22}$. The rate of degradation depends on pesticide chemistry as well as on environmental conditions. Pesticide persistence is oftenly expressed in terms of half-life and the longer half-life shows greater potential for pesticide movement ${ }^{23,24}$.
The relative persistence of Ziram was studied in three different soils of Allahabad region under untreated and farm yard manure treated conditions. In general persistence of Ziram under untreated condition was higher than farm yard manure treated. The addition of farm yard manure (organic matter) has increased the degradation of Ziram in all the soils. So, it is evident that the addition of organic matter to the soils decreased the persistence of Ziram. The greater the amount of organic matter, the greater is the decomposition of Ziram leading to lesser persistence. Thus organic matter promoted the decomposition of Ziram (Fig. 4). The black soil which is rich in organic matter content, showed appreciable decrease in persistence of Ziram. During first three days, farm yard manure treated soil shows maximum degradation of Ziram. The persistence of Ziram has been found in the order alluvial > sandy loam > black soil. This order is inversely related to the adsorption of Ziram by these soils.
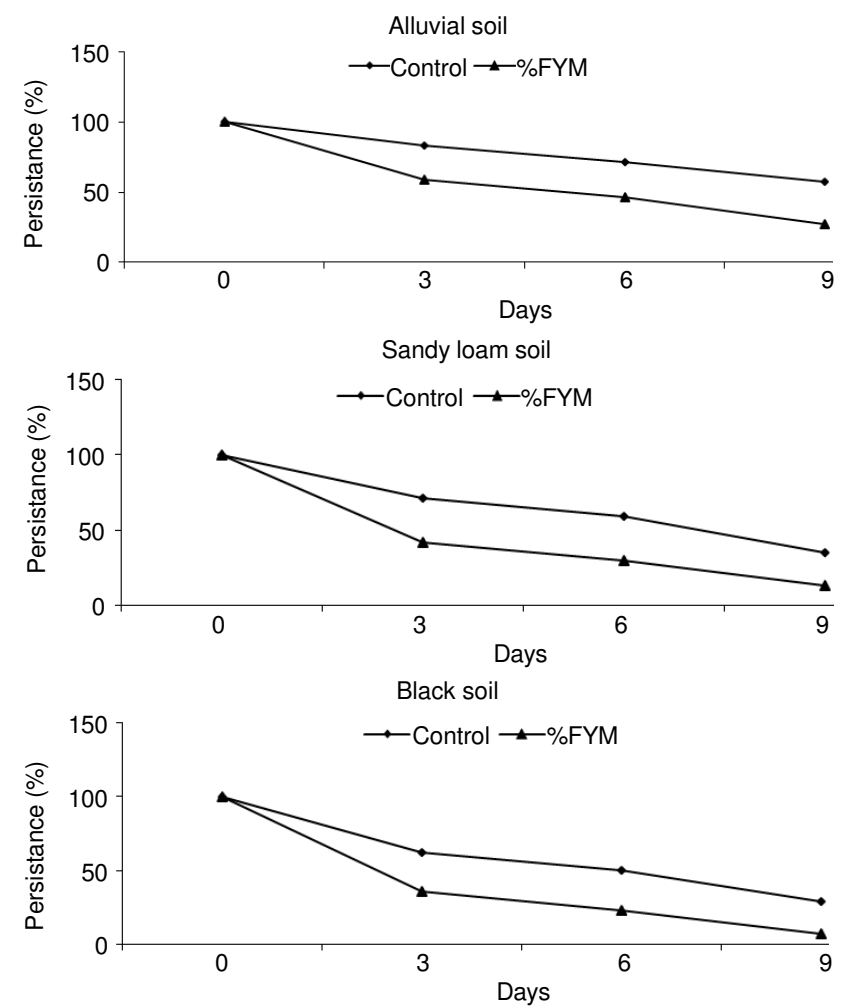

Fig. 4. Persistence of Ziram in untreated and organic matter (farm yard manure) treated soils

The kinetics of degradation of Ziram (Table-4) in soils indicates that Ziram has prolonged persistence in all the soils. The persistence data indicates close correspondence to first order kinetics $\left(r^{2}>0.97\right)$. For each soil, the rate constant and half life value were derived by linear regression analysis of residual concentration on a logarithmic scale against time of incubation. The Table- 4 reveals that the rate constant for black soil treated with farm yard manure is higher i.e., 0.2556 day $^{-1}$ while the half-life $\left(\mathrm{T}_{1 / 2}\right)$ value is maximum in alluvial soil i.e., 11-42 day ${ }^{-1}$. Isselmou et al. ${ }^{25}$ reported that the degradation is inversely related to half life. Hanumantharaju and Awasthi ${ }^{26}$ also reported that half-life of fungicide values are inversely proportional to the rate constant. Thus Ziram has low to moderate persistence. 
TABLE- 4

HALF LIFE $\mathrm{t}_{1 / 2}$ (days), RATE CONSTANT $\mathrm{k}_{\mathrm{deg}}\left(\right.$ day $\left.^{-1}\right)$ OF ZIRAM IN UNTREATED AND TREATED SOIL

\begin{tabular}{|c|c|c|c|c|c|c|c|c|}
\hline \multirow{2}{*}{ Soil } & \multicolumn{4}{|c|}{ Untreated (natural) soil } & \multicolumn{4}{|c|}{ Treated (soil containing FYM) } \\
\hline & $\mathrm{K}_{\mathrm{deg}}$ & slope & $r^{2}$ & $\mathrm{~T}_{1 / 2}$ & $\mathrm{~K}_{\mathrm{deg}}$ & slope & $r^{2}$ & $\mathrm{~T}_{1 / 2}$ \\
\hline Alluvial & $6.07 \times 10^{-2}$ & -0.0263 & 0.99 & 11.42 & $1.373 \times 10^{-1}$ & -0.0596 & 0.99 & 5.05 \\
\hline Sandy loam & $1.039 \times 10^{-1}$ & -0.0451 & 0.98 & 6.67 & $1.980 \times 10^{-1}$ & -0.0859 & 0.97 & 3.50 \\
\hline Black & $1.216 \times 10^{-1}$ & -0.0528 & 0.99 & 5.70 & $2.556 \times 10^{-1}$ & -0.1110 & 0.97 & 2.71 \\
\hline
\end{tabular}

Adsorption of Ziram indicates that soil organic matter is the controlling sorptive medium. The low heat of adsorption calculated from the organic matter normalized Freundlich coefficients suggests that the adsorption is a first order physical process, presumed by solute partitioning. Other physical and chemical properties of soils, such as clay content, $\mathrm{pH}$ and cation exchange capacity do not significantly contribute to the adsorption. The persistence of Ziram in natural and farm yard manure treated soil follows first order kinetics. Degradation was found to be dependent on organic matter and $\mathrm{pH}$ of soil. High organic matter and low $\mathrm{pH}$ increases the residual life of Ziram. Lower persistence of Ziram in the soil is due to rapid rate of degradation at smaller half-life values.

\section{REFERENCES}

1. J.L. Lopez Paz and M. Catala-Icardo, Anal. Chim. Acta, 625, 173 (2008).

2. A.K. Malik, V. Sharma, V.K. Sharma and A.L.J. Rao, J. Agric. Food Chem., 52, 7763 (2004).

3. R.A. Cassella, S. Garrigues and C. de Campos Reinaldo, Talanta, 54, 1087 (2001).

4. O. Tiryaki and C. Temur, J. Biol. Environ. Sci., 4, 29 (2010).

5. O. Yavuz, Asian J. Chem., 19, 3132 (2007).

6. M.M. Arias, E. Paradelo and J. Lopez, J. Agric. Food Chem., 54, 8155 (2006).

7. P.W.M. Augustijn-Beckers, A.G. Hornsby and R.D. Wauchope, Environ. Contam. Toxicol., 137, 4 (1994).

8. P.H. Howard, Handbook of Environmental Fate and Exposure Data for Organic Chemicals: Pesticides, Lewis Publishers, Chelsea, MI, 4 (1989).
9. C.L. Arora, Fundamental of Soil Science, Indian Society of Soil Science, IARI, New Delhi, p. 405 (2002).

10. J.R. Rangaswamy, P. Poornima and S.K. Majumdar, J. Assoc. Off. Anal. Chem., 53, 1043 (1970).

11. S. Gupta, V.T. Gajbhiye and H.P. Agnihotri, Bull. Environ. Contamin. Toxicol., 66, 9 (2001).

12. A.K. Mandal and M. Adhikari, J. Indian Soc. Soil Sci., 43, 561 (1995).

13. A. Valverde-Garcia, E. Gonzalez-Prades, M.V. Sanchez, F. Delrey-Bueno and A. Garcia-Rodriguez, Soil Sci. Soc. Am. J., 52, 1571 (1988).

14. D.K. Sharma, B.C. Verma, S. Sood, N. Verma and K.C. Sood, Pestic. Res. J., 12, 1 (2000).

15. V. Kumar, H.S. Rathore, S. Mital and S. Kumar, Pestic. Res. J., 12, 103 (2000).

16. D. Sharma and M.D. Awasthi, Plant Soil, 195, 293 (1997).

17. N. Singh, J. Agric. Food Chem., 50, 6434 (2002).

18. R.L. Celis, M.C. Cox and J. Hermonsin, J. Environ. Quality, 26, 472 (1997).

19. R. Durovic, J. Gajic-Umiljendic and T. Dordevic, Pestic. Phytomed., 24, 51 (2009).

20. T.H. Hanumantharaju and M.D. Awasthi, Pestic. Res. J., 14, 292 (2002).

21. E. Brandsteterova, J. Lehotay and J. Garaj, J. Chromatogr., 502, 214 (1990).

22. L. Maraim, A. Singh and C. Gupta, Asian J. Chem., 21, 1432 (2009).

23. B. Gupta, R. Manviri and R. Kumar, Biomed. Chromatogr., 26, 69 (2012).

24. M.C. Diez, J. Soil. Sci. Plant Nutr., 10, 244 (2010).

25. O.H. Isselmou, C. Diop, D. Sarr, M. Mbaye, L. Cisse, A. Mbaye, M.D. Gaye-Seye, A. Coly, F. Delattre, O. Oyelakin and A.Tine, Int. J. Chem., 4, 50 (2012).

26. T.H. Hanumantharaju and M.P. Awasthi, J. Indian Soc. Soil Sci., 51, 528 (2003). 